\title{
Common Address Terms in the Data
}

\begin{tabular}{|c|c|}
\hline Abang/Bang & $\begin{array}{l}\text { Indonesian meaning 'older brother,' also used to } \\
\text { address young adult males }\end{array}$ \\
\hline Agan/Aganwati/Gan & $\begin{array}{l}\text { From juragan 'boss'; used as address term among young } \\
\text { people mainly in online interaction }\end{array}$ \\
\hline Bapak/Pak/Pa & $\begin{array}{l}\text { Indonesian for 'father' (originally Javanese); used as } \\
\text { title and address term for adult males }\end{array}$ \\
\hline Bro & $\begin{array}{l}\text { Originally from English, used as address term among } \\
\text { young people, for both female and male addressees }\end{array}$ \\
\hline $\mathrm{Ibu} / \mathrm{Bu}$ & $\begin{array}{l}\text { Indonesian for 'mother' (originally Javanese); used as } \\
\text { title and address term for adult females }\end{array}$ \\
\hline Kakak/Kak & $\begin{array}{l}\text { Indonesian for 'older sibling,' used to address people } \\
\text { considered more senior than the speaker }\end{array}$ \\
\hline Kakang/Akang/Kang & $\begin{array}{l}\text { Sundanese kin term meaning 'older brother'; used to } \\
\text { address young adult males }\end{array}$ \\
\hline Man & $\begin{array}{l}\text { Originally from English, used as address term among } \\
\text { young people, both female and male }\end{array}$ \\
\hline Mang & $\begin{array}{l}\text { Sundanese kin term meaning 'uncle'; used to address } \\
\text { adult males often from working class background; in some } \\
\text { contexts can be used as respectful and endearing term }\end{array}$ \\
\hline Mas & $\begin{array}{l}\text { Javanese kin term meaning 'older brother'; used to } \\
\text { address young adult males }\end{array}$ \\
\hline Mbak & $\begin{array}{l}\text { Javanese kin term meaning 'older sister'; used to } \\
\text { address young adult females }\end{array}$ \\
\hline Nak & $\begin{array}{l}\text { Indonesian for 'child' (from anak), used as address term } \\
\text { for a young child }\end{array}$ \\
\hline $\mathrm{Oom} / \mathrm{Om}$ & $\begin{array}{l}\text { From Dutch meaning 'uncle,' used as a kin term and to } \\
\text { address adult males of comparable age to one's father }\end{array}$ \\
\hline Rek & $\begin{array}{l}\text { Javanese meaning 'child' (from arek), used as address } \\
\text { term among young people, both female and male }\end{array}$ \\
\hline Sis/Sist & $\begin{array}{l}\text { Originally from English, used as address term among } \\
\text { young people, for female addressees }\end{array}$ \\
\hline Teteh/T & $\begin{array}{l}\text { Sundanese kin term meaning 'older sister'; used to } \\
\text { address young adult females }\end{array}$ \\
\hline
\end{tabular}

